\title{
Beyond 2020: Moving Towards New Normal in Medical Education
}

\begin{abstract}
The most unprecedented and challenging year faced by the medical profession and medical education has come to an end. During 2020, COVID-19 has inflicted an unexpected and unprecedented degree of damage and uncertainty on humanity. These profound effects may have an everlasting impact on how future doctors are educated. This situation, therefore, is a transformative juncture to learn and apply new methods and practices in medical education.
\end{abstract}

Karunathilake, I.M

Many medical schools in the South East Asian (SEA) region have managed to face the challenge of transitioning from conventional to a more online-based teaching programme. Many clinical departments have come up with innovative plans to avoid overcrowding during clinical teaching (Tenzin et al, 2020).

Even though Technology-Enhanced Medical Education still remains an unfamiliar territory for many trainers, COVID-19 pandemic has provided a prospect for digital transformation in medical education. Technology-enhanced medical education including Simulation, Elearning/M-learning, Virtual Patients/Virtual communities and Artificial Intelligence is considered to be effective in promoting selfdirected learning. These methods are preferred in providing Continuous Professional development (CPD) and postgraduate medical education. As medical educators of the South East Asian Region (SEAR), we have overcome the challenge of cost effectiveness by using free open source software and programmes in E-learning, Mobile Learning (M-Learning) and

Professor Indika Karunathilake,

Department of Medical Education, Faculty of Medicine, University of Colombo, Sri Lanka.

Email:karunathilake@hotmail.com

Virtual Reality (VR). (Yapa et al, 2013; Tenzin et al, 2020)
Many have found online teaching to be effective as it enables the availability of remote lecturers who otherwise travel long distances to deliver lectures especially in universities like

Eastern universities. Most students and educators feel that this has improved student participation in online classes where attendance has been nearly $100 \%$, which was rarely seen in face to face traditional lectures. Move towards more technology-based teaching method as well as assessments and evaluation methods will also impact the ethos of the future generation of doctors and prepare them to face a world where there is a high digital literacy rate.

Adapting to the new normal requires several other transformations such as in financial, infrastructure, hardware, resource management, etc. This should be achieved by implementing a well thought out plan to utilize the existing available resources. Digitalization of medical education required a total paradigm shift of teaching and we are yet to make the transition fully. The pandemic has brought to the fore the importance of institutional readiness in making this transition (Karunathilake et al, 2020)

As such owing to the novelty of this experience both the staff and the students will benefit immensely from training programs on the utilization of the available facilities and different online teaching tools. E-learning adaptation is to thus ensure the alignment of new tools to the educational needs and requirements of its users. Additionally, developing soft skills such as ethics, cognitive skills, empathy should be thought in face-to-face discussions. Changing behaviour and attitudes is also challenging when using online platforms.

In the new normal, conventional ward teaching will be converted to small group clinical classes merged with online ward classes and interactive videos. This digital transition will minimize the risk of disease transmission.

DOI: http://doi.org/10.4038/seajme.v14i2.271 
Since using real patients when conducting exams carries a high risk, the use of simulated patients to assess clinical skills, examination techniques, and communication skills would be an option. To reap the benefits of this transition even beyond the pandemic student-driven active learning should be encouraged. In this light, the accessibility to resources is fundamental to its success (Karunathilake et al, 2020).

Medical education worldwide is changing and SEAR is not an exception. The challenges caused by COVID-19 have become a blessing in disguise for promoting innovative use of technology in Medical Education.

\section{References}

Tenzin, K., Karunatilaka, I.M., Rimal, J., Wangdi, P., Gyamtsho, S., Tobgay, T., Dorji, G., Pradhan, D., Tshering, D., Supe, A. and Jayasinghe, S., (2020) The making of 21st century doctors of Bhutan; use of artificial intelligence, big data and values appropriate for the new normal in the 21st century. South-East Asian Journal of Medical Education, 14(1).

Yapa, Y.M.M.M., Dilan, M.M.N.S., Karunaratne, W.C.D., Widisinghe, C.C., Hewapathirana, R. and Karunathilake, I.M. (2012) Computer Literacy and Attitudes towards eLearning among Sri Lankan Medical Students. Sri Lanka Journal of Bio-Medical Informatics, 3(3), pp.82-96.

Karunathilake, I.M., Dissanayake, V.H.W., Yasawardena, S., Abegunawardena, A., Raviraj, S., Wijesinghe, P.S., Anthony, A.A., Wijesinghe, R.A.N.K., Bowatte, S., Wickramaratne, N. and Pathirana, K.D., 2020. The new normal of medical education-challenges and opportunities. South-East Asian Journal of Medical Education, 14(1) 